See Article page e269.

\section{Commentary: A new reason to breathe easy about spinal cord ischemia?}

\author{
Danisa K. Daubenspeck, DO, and \\ Mark A. Chaney, MD
}

Hydrogen gas has emerged as a therapeutic tool for various entities involving ischemia-reperfusion injury (IRI). Animal studies have shown that inhaled hydrogen gas protects against spinal cord IRI. Kimura and colleagues ${ }^{1}$ take another step forward, revealing a potential mechanism for these beneficial effects.

In their comprehensive, well-designed, prospective, randomized rat study, they reveal that inhalation of varying levels of hydrogen gas $(1 \%, 2 \%$, or $3 \%)$ before standard induction of spinal cord IRI exerts concentration-dependent protective effects on motor function, seen via histopathologic examination. Furthermore, inhaled hydrogen gas also attenuated spinal cord IRI-induced increases in ventral horn glutamate levels in a concentration-dependent manner. Lastly, the protective effects of inhaled hydrogen gas were not observed in animals receiving a glutamate transporter- 1 inhibitor and ventral horn glutamate levels increased in these animals as well. Their results confirm findings of other investigators demonstrating spinal cord IRI-protective effects of inhaled hydrogen gas. Their results also indicate that glutamate transporter-1 may play an important role in this process.

Despite advances in surgical techniques, spinal cord IRI remains a significant problem after both open repair and endovascular thoracoabdominal aneurysm repair, with incidence reported from $10 \%$ to $30 \% .^{2-4}$ Mechanism of spinal cord IRI is postulated to be caused by alterations in spinal cord perfusion pressure; due to hypotension,

\footnotetext{
From the Department of Anesthesia and Critical Care, University of Chicago Medical Center, Chicago, Ill.

Disclosures: The authors reported no conflicts of interest.

The Journal policy requires editors and reviewers to disclose conflicts of interest and to decline handling or reviewing manuscripts for which they may have a conflict of interest. The editors and reviewers of this article have no conflicts of interest.

Received for publication May 3, 2021; revisions received May 3, 2021; accepted for publication May 4, 2021; available ahead of print May 7, 2021.

Address for reprints: Mark A. Chaney, MD, Department of Anesthesia and Critical Care, University of Chicago Medical Center, 5841 S Maryland Ave, MC 4028, Chicago, IL 60637 (E-mail: MChaney@dacc.uchicago.edu).

J Thorac Cardiovasc Surg 2022;164:e285 0022-5223/\$36.00

Copyright $(2021$ Published by Elsevier Inc. on behalf of The American Association for Thoracic Surgery

https://doi.org/10.1016/j.jtcvs.2021.05.007
}

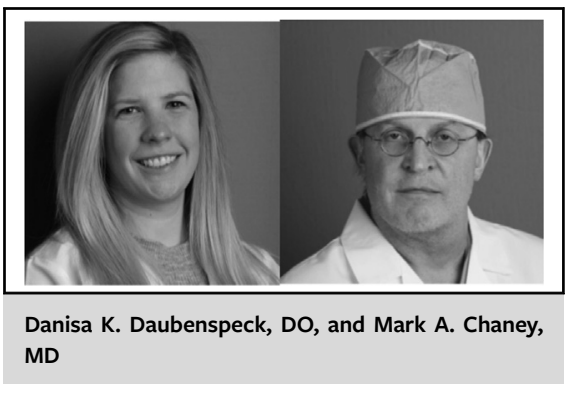

$$
\begin{aligned}
& \text { CENTRAL MESSAGE } \\
& \text { Many techniques exist for pre- } \\
& \text { venting spinal cord ischemia- } \\
& \text { reperfusion injury; however, no } \\
& \text { one is universally sufficient. } \\
& \text { Hydrogen gas has emerged as a } \\
& \text { new potentially clinically useful } \\
& \text { strategy. }
\end{aligned}
$$

increased cerebrospinal fluid (CSF) pressure, or interruption of flow through segmental arteries (SAs) during aortic clamping or during reperfusion after unclamping. ${ }^{2}$ Cause of spinal cord IRI during endovascular thoracoabdominal aneurysm repair is believed to be due to coverage of SAs by graft location, yet a recent pilot study shows magnetic resonance imaging and histologic findings of spinal cord IRI in endovascular thoracoabdominal aneurysm repair may be much different then open repair, suggesting a different mechanism of injury. ${ }^{3}$ Goals of management strategies address these disparate causes. CSF drainage, among the most studied options, involves perioperative intrathecal catheter placement, with goal of decreasing CSF pressure. ${ }^{2,4}$ Although effective, it comes with significant risk of complications, including neuraxial bleeding, infection, or spinal headache. ${ }^{2}$ Alternatively, maintenance of high mean arterial pressure $(>80 \mathrm{~mm} \mathrm{Hg}$ ) may also increase spinal cord perfusion pressure, with improved outcomes when employed with CSF drainage. ${ }^{2}$ Another technique is hypothermia, via passive cooling, localized via epidural saline infusion, or deep hypothermic circulatory arrest. ${ }^{4}$ Other options include selective reimplantation of SAs or distal aortic perfusion via an atriofemoral bypass circuit. Pharmacologic interventions such as corticosteroids or barbiturates act to decrease metabolic rate of the spinal cord or function as free radical scavengers to minimize reperfusion injury. $^{2}$ 
Despite the vast number of various strategies available, no single tactic has proven sufficient to completely abolish spinal cord IRI. Hydrogen gas may be effective in reducing oxidative stress after cardiac arrest, and is now potentially effective against spinal cord IRI. ${ }^{1}$ The ability to potentially have a universal, safe, and easily applied technique to avoid the devastating results of spinal cord IRI is a very exciting prospect, and the results of this study conducted by Kimura and colleagues ${ }^{1}$ indicate the possible clinical usefulness of hydrogen gas and also open up new avenues for further research.

\section{References}

1. Kimura A, Suehiro K, Mukai A, Fujimoto Y, Funao T, Yamada T, et al. Protective effects of hydrogen gas against spinal cord ischemia-reperfusion injury. J Thorac Cardiovasc Surg. 2022;164:e269-83.

2. Awad H, Ramadan ME, El Sayed HF, Tolpin DA, Tili E, Collard CD. Spinal cord injury after thoracic endovascular aortic aneurysm repair. Can J Anaesth. 2017;64: 1218-35.

3. Awad H, Tili E, Nuovo G, Kelani H, Ramadan ME, Williams J, et al. Endovascular repair and open repair surgery of thoraco-abdominal aortic aneurysms cause drastically different types of spinal cord injury. Sci Rep. 2021;11:7834.

4. Acher C, Acher CW, Marks E, Wynn M. Intraoperative neuroprotective interventions prevent spinal cord ischemia and injury in thoracic endovascular aortic repair. J Vasc Surg. 2016;63:1458-65.
See Article page e269.

\section{Commentary: Hydrogen: Lightweight molecule takes on a heavyweight problem}

\author{
John N. Kheir, MD, ${ }^{\mathrm{a}, \mathrm{b}}$ and James A. DiNardo, $\mathrm{MD}^{\mathrm{c}, \mathrm{d}}$
}

Diatomic hydrogen $\left(\mathrm{H}_{2}\right)$ is the lightest and most abundant molecule in the universe. Hydrogen's reactivity with oxygen is well recognized as a thermodynamically favorable redox reaction that forms water. $\mathrm{H}_{2}$ 's small size results in unsurpassed diffusivity (even diffusing through steel), enabling it to reach therapeutic targets effectively even in low-flow states. In vivo, inhaled $\mathrm{H}_{2}$ undergoes solubilized transport to the tissues and undergoes redox reactions with reactive oxygen species (ROS) within the mitochondrion, resulting in a substantial arteriovenous difference in dissolved $\mathrm{H}_{2}$ content $(\sim 10 \mathrm{ng} / \mathrm{mL}){ }^{1}$ Shown in Figure 1, $\mathrm{H}_{2}$ is an ideal therapy for ischemia and reperfusion, where the underlying pathophysiology is mitochondrial oxygen deprivation leading to the subsequent formation of ROS. Unreduced ROS initiate a complex cascade that leads to

From the Departments of ${ }^{\mathrm{a} C}$ ardiology and ${ }^{\mathrm{c}}$ Anesthesiology, Perioperative and Pain Medicine, Boston Children's Hospital; and Departments of ${ }^{\mathrm{b}}$ Pediatrics and ${ }^{\mathrm{d}}$ Anaesthesia, Harvard Medical School, Boston, Mass.

Disclosures: The authors reported no conflicts of interest.

The Journal policy requires editors and reviewers to disclose conflicts of interest and to decline handling or reviewing manuscripts for which they may have a conflict of interest. The editors and reviewers of this article have no conflicts of interest.

Received for publication April 30, 2021; revisions received April 30, 2021; accepted for publication May 3, 2021; available ahead of print May 7, 2021.

Address for reprints: James A. DiNardo, MD, Department of Anesthesiology, Perioperative and Pain Medicine, Boston Children's Hospital, 300 Longwood Ave, Boston, MA 02115 (E-mail: james.dinardo@ childrens.harvard.edu).

J Thorac Cardiovasc Surg 2022;164:e286-7

0022-5223/\$36.00

Copyright (c) 2021 by The American Association for Thoracic Surgery

https://doi.org/10.1016/j.jtcvs.2021.05.001
Check for updates

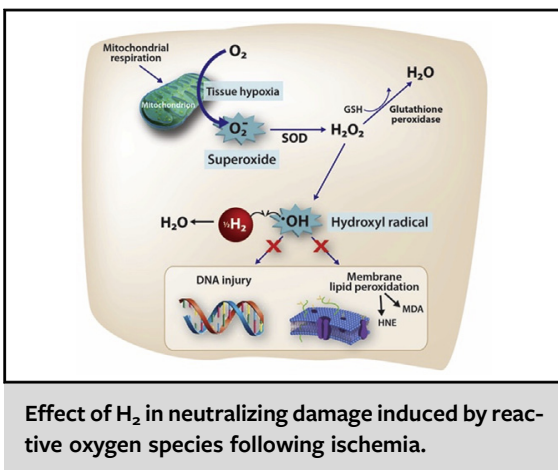

CENTRAL MESSAGE

Reperfusion following ischemia

produces reactive oxygen species

$\mathrm{O}_{2} \bullet \bullet, \mathrm{H}_{2} \mathrm{O}_{2}$, and $\bullet \mathrm{OH}$. These

species react with DNA, lipids, and

proteins, resulting in cellular injury

and death. $\mathrm{H}_{2}$ reduces $\bullet \mathrm{OH}$ to

$\mathrm{H}_{2} \mathrm{O}$.

oxidation of DNA, lipid membranes, and other structures culminating in apoptosis.

In this issue of the Journal, Kimura and colleagues ${ }^{2}$ describe a series of well-controlled experiments demonstrating that $\mathrm{H}_{2}$ attenuates the effects of experimental spinal ischemia in a dose-dependent fashion with improved motor function, reduced histopathologic injury, and reduced cerebrospinal fluid glutamate and hydroxyperoxide concentrations. These findings are consistent with a preponderance of evidence that $\mathrm{H}_{2}$ 's primary effect is related to reactivity with and chemical reduction of oxygen species. In addition to glutamate, mitigation of this central pathology has been 